\title{
Disinfection by-products and extractable organic compounds in South African tap water
}

\author{
C Nothnagel, $K$ Kotte, JJ Pienaar, PG van Zyl and JP Beukes*
}

\begin{abstract}
.
An important step in urban purification of drinking water is disinfection by e.g. chlorination where potential pathogenic micro-organisms in the water supply are killed. The presence of organic material in natural water leads to the formation of organic byproducts during disinfection. Over 500 of these disinfection by-products (DBPs) have been identified and many more are estimated to form during the disinfection step. Several DBPs such as trihalomethanes (THMs), which is carcinogenic, poses serious health risks to the community. There is very few quantitative data available which realizes the actual levels of these compounds present in drinking water. The levels of four THMs present in drinking water were measured. It included chloroform, bromodichloromethane, chlorodibromomethane and bromoform. Although microbiological parameters are considered to get more attention than disinfection by-products, the measurement of the levels of these compounds in South-African drinking water is essential together with establishing minimum acceptable concentration levels. The target range for total trihalomethanes (TTHMs) established by the US EPA at the end of 2003 is $0-0.08 \mathrm{ug} / \mathrm{mL}$. The aim of this paper is to create an awareness of the problem as well as presenting preliminary results obtained with the method of analysis. Preliminary results indicate that urgent attention must be given to the regulation and monitoring of DBPs in South African drinking water.
\end{abstract}

Keywords: drinking water, taps, South African municipal areas, disinfection by-products $\mathrm{DBP}$ ), organic compounds (OC), trihalomethanes, chloroform, bromodichloromethane, chlorodibromomethane and bromoform.

Disciplines: Chemistry, environmental chemistry and ecotoxicology.

* Carien Nothnagel, (E-mail: 13066544@nwu.ac.za) is an M.Sc-candidate in analytical chemistry, at North-West University's Potchefstroom campus. Dr Karsten Kotte is a post-doc in environmental chemistry and ecotoxicology. Prof. JJ (Kobus) Pienaar, is leader of the Atmospheric Chemistry Research Group in the School of Physical and Chemical Sciences at North-West University's Potchefsrteroom campus. Dr PG (Pieter) van Zyl and Dr JP (Paul) Beukes are also chemists and members of the group. 


\section{Introduction}

The widespread disinfection of drinking water, which is approximately 100 years old, is regarded to be the major instrument in combating various waterborne diseases. However, modern methods of water treatment face the growing challenge of balancing the risks of waterborne pathogens against the risks that disinfection by-products (DPBs) may pose. DBPs are a wide range of unwanted organic compounds formed by chemical reactions of disinfectants typically used in water treatment such as chlorine, chlorine derivates and ozone, with the organic matter present in natural water. Since the first DBPs were found by Rook [1] and Bellar [2] 30 years ago, more than 250 DBPs have been identified. It is estimated that the amount of DBPs identified thus far only contributes to about 50 per cent of the actual amount of DBPs present based on the number and weight perception [3, 4, 5]. Except for DBPs there are also organic compounds (OC) present in tap water. They originate from sources, other than those formed during the treatment process. In most instances the sources of these compounds are either from impurities present in untreated water or from contamination within the distribution systems due to pipe leakages. Some DBPs and OCs present in drinking water are potentially hazardous to humans (e.g. carcinogenic, cause harm to the liver, kidney, brain, reproductive- and nervous system) and may also have an influence on the aesthetic quality of tap water such as odors and taste.

In the last 30 years significant research efforts have been initiated by developed countries aimed at improving the understanding of formation, occurrence and health effects of DBPs and OCs present in drinking water. In contrast to this development similar research in South Africa has declined since the early 1990s. In consequence of this tendency there is currently very little or no data available regarding the occurrence and formation of DBPs and OCs in South African drinking water [6,7]. According to a survey conducted by Holzhausen in 2005 [9] only 58 per cent of South African authorities responsible for water services monitor the quality of the local drinking water on a regular basis.

The World Health Organization (WHO) and most developed countries have well defined regulations and guidelines to protect consumers from elevated levels of DBPs and OCs without compromising on the biological safety of drinking water. Current legislation on drinking water quality in South Africa reflects an anomaly in the regulation of microbiological quality and organochemical characteristics. In particular disinfection by-products, pesticides and other OCs receive little or no attention from the policymakers. As a result, the current South African National Standard on drinking water only provides regulations for total trihalomethanes (TTHM), dissolved organic carbons and phenols. 


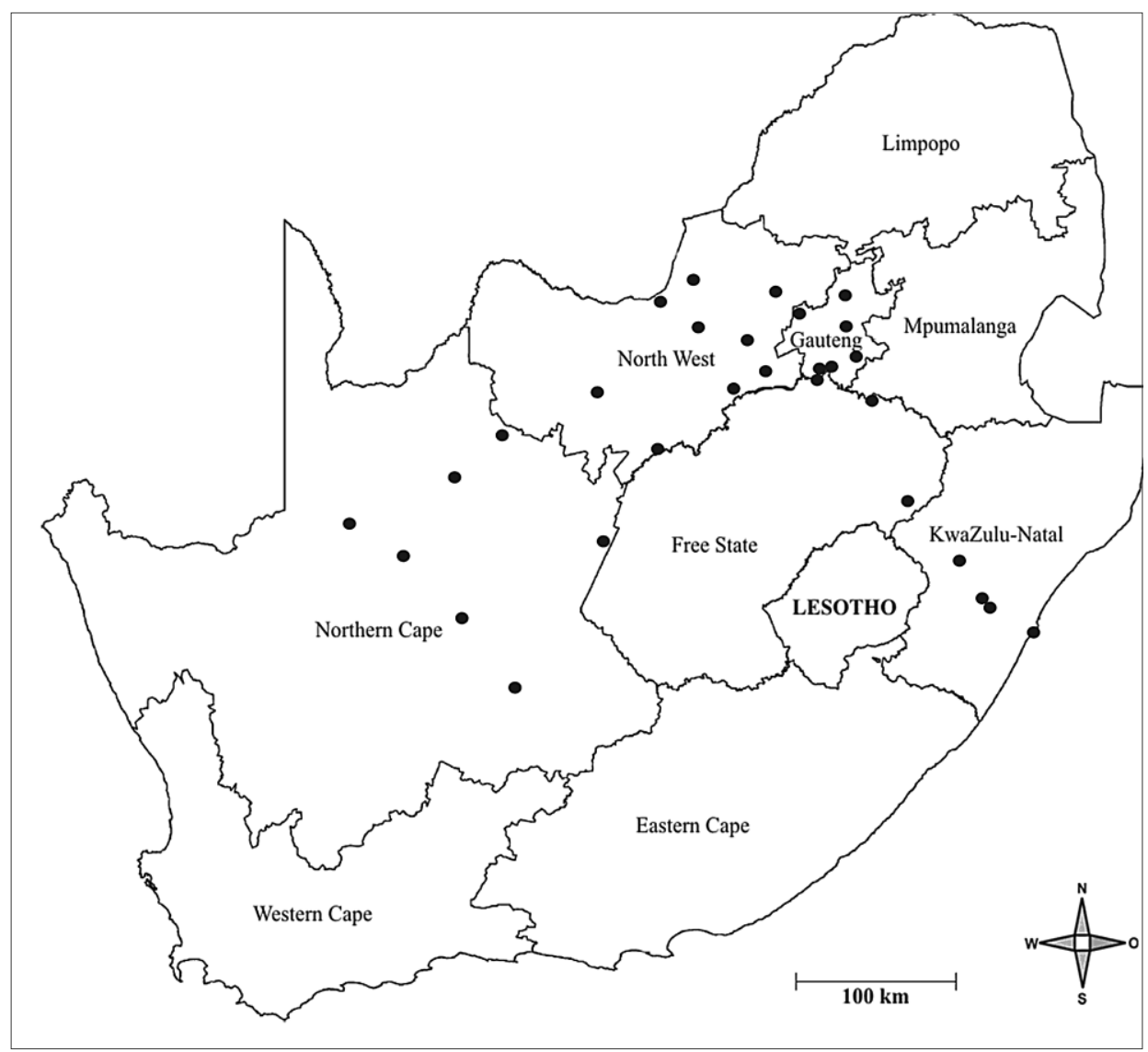

Figure 1 Sample sites in South-Africa.

\section{Method}

Samples were taken from publicly and regularly used water taps in 31 municipal areas across South Africa (Figure 1). Each sample was immediately closed off in a glass vial. They were stored in a fridge at temperatures below $10^{\circ} \mathrm{C}$ and above freezing point until the extraction was performed. The extraction and analytical method used was adapted from the EPA 551.1 standard operating procedure. This particular EPA method is used to determine DBPs such as trihalomethanes and haloacetonitriles, chlorinated solvents and pesticides. The procedure was adapted to apply to small scale laboratory extraction and analysis. Liquid-liquid extraction was carried out using $0.5 \mathrm{ml}$ Methyl-t-butylether to extract trihalomethanes from $5 \mathrm{ml}$ water. The extracted sample was analyzed on a gas chromatograph (GC) coupled with a time-offlight mass spectrometer detector (MS-TOF). This instrument is a powerful analytical tool providing fast and sensitive analyses and has not previously been used for the detection of DBPs in drinking water. 
Separation of complexes in a GC occurs due to differences in polarities and affinities of the various compounds. The sample is inserted into a column and is carried with an inert gas (mobile phase). As it moves through the column separation of the compounds present in the sample takes place due to their interaction with a packing material (stationary phase) inside the column, which results in different retention times for the complexes (time for a compound to move through the column). The separated compound is then detected with a MS-TOF and identified on its specific mass.

\section{Results and Discussion}

Measurement of the concentration levels of four trihalomethane (THM) compounds (trichloromethane, dichlorobromomethane, dibromochloromethane, tribromomethane), which are DBPs typically found in drinking water, were selected for this investigation. Four compounds were chosen to increase the certainty of the presence of THMs in a water sample. In order to determine concentrations of these compounds in real samples it is necessary to compare results with a reference sample, which is called a standard solution. A standard sample solution containing known concentrations of these compounds was purchased. Figure 2 shows the chromatogram obtained with the GC/MS-TOF. The four peaks are clearly separated with the first peak for trichloromethane emerging after $\sim 550 \mathrm{~s}$ and last peak for tribromomethane appearing at $1320 \mathrm{~s}$.

Figure 2 Chromatogram offour trihalomethanesfound in water samples.

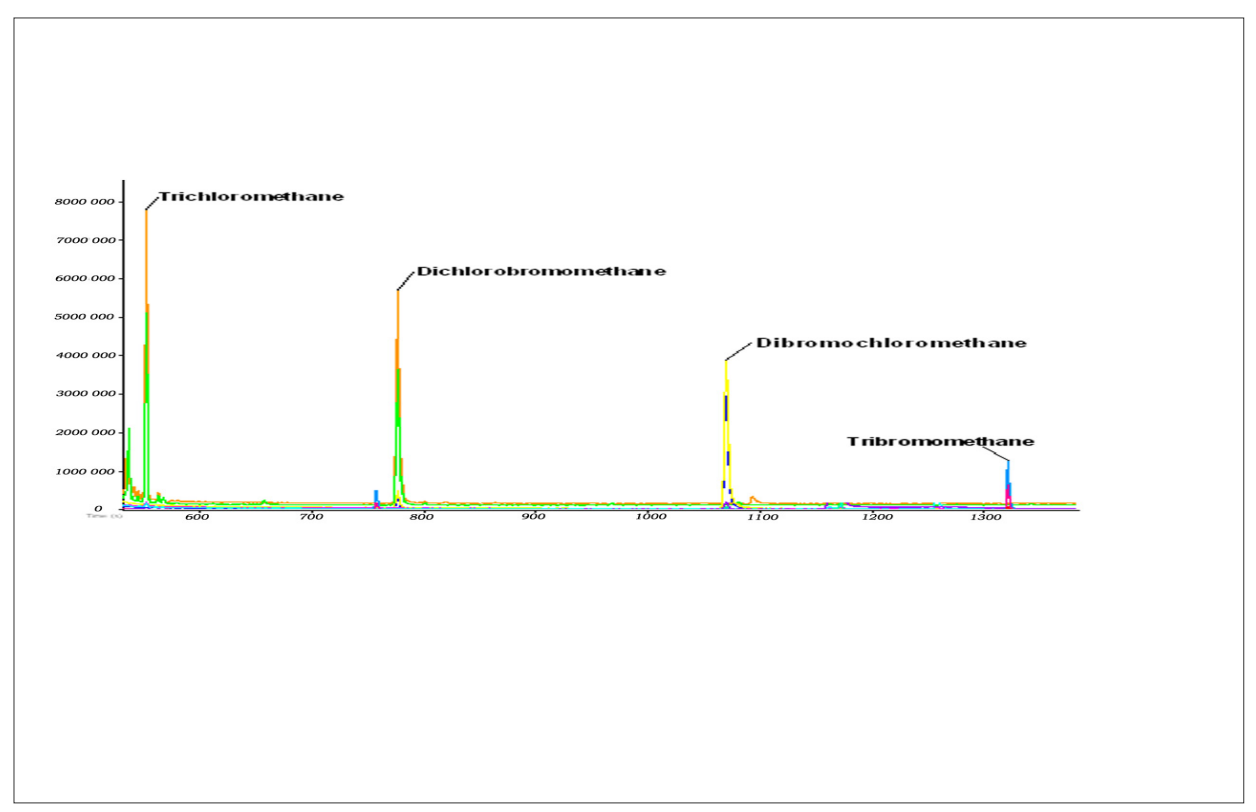


In Figure 3 the preliminary results obtained for 10 of the 31 municipal areas are shown. The concentrations are given in microgram per milliliter $(\mathrm{ug} / \mathrm{mL}$ ). The concentrations of the TTHMs measured vary from as high as $1.25 \mathrm{ug} / \mathrm{mL}$ for Potchefstroom to the lowest value of $0.2 \mathrm{ug} / \mathrm{mL}$ for Vereeniging. These differences can be expected because each municipality receives its drinking water from different water purifying plants. The source of the water that is purified and the level of disinfection will differ for each purifying plant. The type and amount of organic compounds present in the unpurified water will vary for each place, which will determine the concentration levels of TTHMs formed during disinfection.

When taking into consideration that the target range established by the US EPA for TTHMs is $0-0.08 \mathrm{ug} / \mathrm{mL}$, these values determined are high and raises concern. Even the lowest concentrations measured at Vereeniging and Magaliesburg are well above the US EPA target range. The concentrations measured at Potchefstroom and Groblershoop are especially high and action should be taken to decrease these levels.

Figure 3 Preliminary results of ten of the 31 communities.

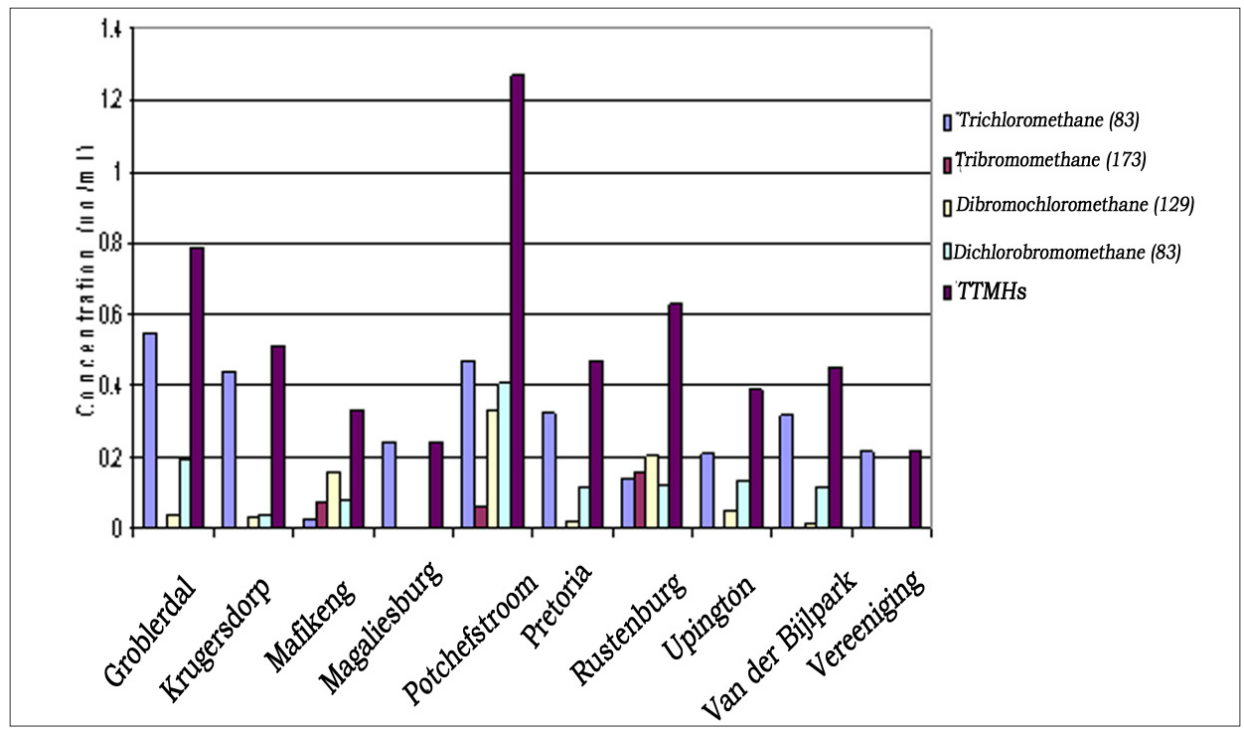

The analyses of these samples were carried out using onedimensional GC/MS-TOF and the presence of only four THMs was determined. The instrument however has the ability to give twodimensional GC/MS-TOF graphs, where overlapping compound peaks are separated on a second column. This allows for the determination of more compounds present in the sample. This feature will be used 
later to increase the total amount of THMs and DBPs detected.

It is clear that a full assessment of TTHMs and other DBPs present in drinking water across the country should be conducted when examining these preliminary results. Another motive for a comprehensive evaluation is to determine a target range, which is feasible for South African conditions. Benchmark targets established by the US Environmental Protection Agency (EPA) are not necessary applicable to unique South African environmental conditions.

The study is still in an early stage and the method will further be optimized. Considering the preliminary results obtained, it can clearly be seen that urgent attention must be given to the regulation and monitoring of DBPs and OCs in South African drinking water.

\section{References}

Bellar, T.A.; Lichtenberg, J.J.; Kroner, R.C., 1974. The Occurrence of Organohalides in Chlorinated Drinking Waters, J. Am. Wat. Wks. Ass., Vol. 66 (12), 703-706.

Krasner S.W., Weinberg H.S., Richardson S.D., Pastor S.J., Chinn R., Sclimenti M.J., Onstad G.D., Thruston A.D., 2006. Occurrence of a New Generation of Disinfection Byproducts, Environ. Sci. Technol. 40, 7175-7185.

Meintjies E., Maharaj V., 1992. Evaluation of South African raw and drinking water supplies for volatile organic complexes potentially hazardous to human health. Wat. Sci. Tech., 26 (911), 2117-2120.

Richardson S.D., Plewa M.J., Wagner E.D., Schoeny R., DeMarini D.M., 2007. Occurrence, genotoxicity, and carcinogenicity of emerging disinfection by-products in drinking water: A review and roadmap for research, Mutat. Res., 636, 178-242.

Rook, J.J., 1974. Formation of haloforms during chlorination of natural waters. Water Treatment Examiner 23, pp. 234-243.

Van Steenderen R.A., Pieterse M.J., Bourne D., 1991. THM formation in potable waters with reference to related variables and health data bases, Water SA, 17 (4), 269-272.

Weinberg, H., 1999. Disinfection Byproducts in Drinking Water: The Analytical Challenge. Analytical Chemistry News \& Features, Volume 71 (23), 1999, 801A-808A. 